\title{
Influence of arbuscular mycorrhizal fungi (AMF) on plant competition for growth of a legume and a grass plant species
}

\author{
Sultana, $\mathbf{J}^{1}$, Siddique, M. N. A $^{2 *}$, Miao, K. $^{1}$ and Abdullah, M. R. ${ }^{3}$
}

${ }^{1}$ Master of Organic Agriculture, Wageningen University, Wageningen, the Netherlands

${ }^{2}$ Soil Resource Development Institute, District office, Pabna, Bangladesh, *Phone: 088073165495

${ }^{3}$ Dept. of Crop Botany, Bangladesh Agricultural University, Mymensingh, Bangladesh

$\triangle$ For any information: Siddique, MNA (email: siddique.mna@live.com)

First version available online: 04 September 2014, Revised and published: 14 May 2017.

\begin{abstract}
AMF has considerable influence on plant nutrition uptake, competition between the legume (Trifolium incarnatum) and a grass (Anthoxanthum odoratum) is influenced by the presence of Arbuscular Mycorrhizal Fungi (AMF) in this study. AMF has the ability to change the nutrient distribution between plants which may lead to changes in competitive relationships in plant communities. Pot experiments with a replacement design were conducted to test the influence of $A M F$ isolates and a non AMF control on the competitive relationships of those plant pairs. Key consideration for the study was AMF influence on growth of legume and grass plants when grown individually or in combination of two plants and measured by the dry weight of biomass. Results revealed that AMF stimulates the plant growth of legume and negative effect on grass plant; number of root nodules of legume plant has positive effect in monoculture \& mixture. While in competition, legume plant increased biomass in absence of AMF but the relative yield of the grass plant decreased or remains equal and AMF affects the competitive relationship between legume and grass plant.
\end{abstract}

Key Words: Arbuscular mycorrhizal fungi, Legume, Grass, Growth and Nutrient competition

Cite Article: Sultana, J., Siddiuqe, M. N. A., Miao, K. and Abdullah, M. R. (2017). Influence of arbuscular mycorrhizal fungi (AMF) on plant competition for growth of a legume and a grass plant species. Journal of Bioscience and Agriculture Research, 01(02), 85-91.

Crossref: https://doi.org/10.18801/jbar.010214.10

Article distributed under terms of a Creative Common Attribution 4.0 International License.

\section{Introduction}

Arbuscular Mycorrhizal Fungi (AMF) is an important component of soil communities in many temperate and tropical ecosystems. It is associated with most species of terrestrial plants (Allen et al. 1995). AMF has considerable influence on plant nutrition uptake. It enhances the uptake of phosphorus and also other immobile nutrients which are required by plants (Smith and Read, 1997). 
With AMF associations plants may receive more than $50 \%$ of phosphorus (Jakobsen et al. 1992). The growth and composition of plant communities are greatly influenced by plant competition (Aerts, 1999). Abiotic factors such as nutrient availability and climate influence plant Competition. Plant competition also influenced by interactions with other organisms such as herbivores, pathogens and mutualists (Hetrick et al. 1994; Van der Putten and Peters 1997; Hart et al. 2003). This investigation focused on the influence of Arbuscular Mycorrhizal fungi (AMF) on plant competition.

Different plant species do not profit equally from AMF. Some plants are capable of acquiring more nutrients from the AMF than others (Smith and Read, 1997). The symbiosis between plants and AMF is non-specific. Competing plant species can be interconnected by mycorrhizal hyphal networks. Carbon and nutrients may transfer from one plant to another via such hyphal networks; it has even been reported by several authors (Grime et al. 1987; Newman 1988; Simard et al. 2002). Hence, AMF has the ability to change the nutrient distribution between plants which may lead to changes in competitive relationships in plant communities.

Different studies have investigated the effect of the presence of AMF on plant competition (Fitter 1997; Hamel et al. 1992; Hartnett et al. 1993; Hetrick et al. 1994; West 1996; Marler et al. 1999). This experiment focused specifically on competition between legumes and other plant species. Legumes are of particular interest because they form symbioses with two group ground organisms that influence plant nutrition and AMF and Rhizobia. Rhizobia are bacteria that able to convert atmospheric nitrogen into ammonium that can be used with legumes (Werner, 1992). Legumes are often highly dependent on AMF to supply extra phosphorus required for nitrogen fixation by plants. At the low phosphorus levels, nitrogen fixation can be partly or completely inhibited in the absence of AMF.

This study tested whether competition between the legume (Trifolium incarnatum) and a grass (Anthoxanthum odoratum) is influenced by the presence of AMF. Pot experiments with a replacement design, and tested the influence of AMF isolates and a non AMF control on the competitive relationships of the plant pairs.

This poses the question whether AMF influence growth of legume and grass plants when grown individually or in combination of two plants, and measured by the dry weight of biomass. Thus, few null hypothesis was accounted during the study: a) there will be no change in the yield of legume plants measured in the dry weight of biomass when AMF is added compared to when no AMF is added, b) there will be no change in the yield of grass plants measured in the dry weight of biomass when AMF is added compared to when no AMF is added, c) there will be no change in the number of root nodules of legume plant in monoculture or in combination when AMF is added compare to when no AMF is added, and there will be no change in competitive interaction in the yield of legume and grass plants measured in the dry weight of biomass; AMF is added compared to when no AMF is added.

\section{Materials and Methods}

Plants: Legume - Trifolium incarnatum (supplier Bijenhuis Wageningen) and Grass- Anthoxanthum odoratum (supplier Cruydt-hoeck Nijberkoop) was used for this study

Soil: Droevendaal soil (Typic Endoaquoll) with poor nutrient quality was used and the soil pH was 6.08. The soil was collected at geocoordinate $52.03^{\circ} \mathrm{N}$ and $05.67^{\circ} \mathrm{E}$, Wageningen, Netherlands. Soil contains $1.2 \mathrm{mg} \mathrm{Nkg}^{-1}$ soil in total $\left(0.7 \mathrm{mg} \mathrm{N}^{-\mathrm{NH}_{4}} \mathrm{~kg}^{-1}\right.$ soil, $0.5 \mathrm{mg} \mathrm{NO}_{3}+\mathrm{NO}_{2} \mathrm{~kg}^{-1}$ soil).

Inoculation: AMF inoculated on top of 3 species of AMF with $20 \mathrm{ml}$.

Timing of treatments: Plants germination started on the $7^{\text {th }}$ of August, plants transplanted to biger pots on the 17th of August and AMF added on the $4^{\text {th }}$ of September and plants were harvested on the $28^{\text {th }}$ of August.

Treatments: The following treatments were applied for each plant species: with/without Arbuscular Mycorrhizal Fungi (AMF). For each treatment there were four replicates. 
To investigate the effects of inoculation with AMF on the plant growth, several measurements were carried out in the $6^{\text {th }}$ week after planting. The measured response variables consisted of dry weight biomass of both the shoot and the root and root nodules.

Competition between T. incarnatum and A. odoratum was investigated with two plants per pot in the monocultures and $1+1$ plant per pot in the mixtures. With AMF, and a control, and four replicates, this resulted in a total of 24 pots.

After harvest, sand was removed and plants were washed. Then plants were divided into shoots and roots. After drying shoots and roots were weighed.

The Relative Yield Total (RYT), which is a measure of the relative productivity of a mixture, and the Aggressively Index, which is a measure of relative performance of the two plant species, compared with each other, were calculated by equations 1 and 2 respectively (de Wit, 1960; McGilchrist \&Trenbath, 1971):

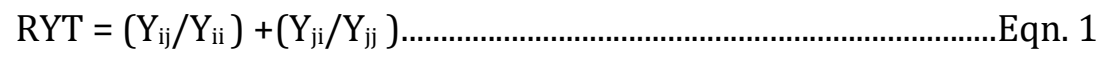

Aggressivity index $=\left(\mathrm{Y}_{\mathrm{ij}} / \mathrm{Y}_{\mathrm{ii}}\right)-\left(\mathrm{Y}_{\mathrm{ji}} / \mathrm{Y}_{\mathrm{jj}}\right)$........................................Eqn. 2

Here, $Y_{i j}$ and $Y_{i i}$ are the shoot yields of $T$. incarnatum in mixture and monoculture respectively. Similarly, $Y_{\mathrm{ji}}$ and $\mathrm{Y}_{\mathrm{ij}}$ are the shoot yields of $A$. odoratum in mixture and monoculture. The factor $\left(\mathrm{Y}_{\mathrm{ij}} / \mathrm{Y}_{\mathrm{ii}}\right)$ and $\left(Y_{\mathrm{ji}} / Y_{\mathrm{jj}}\right)$ are relative yields of the plant species in mixture. The lower the aggressively index, the more competitive T. incarnatum is compared with A. odoratum.

AMF dependency of each plant species in monoculture or in mixture was calculated (Van der Heijden, 2002; Eqn. 3).

AMF Dependency $=1-(b / a), a \geq b,-1+(a / b), a<b$ Eqn. 3

Where ' $a$ ' is the average biomass of the treatments with AMF, and ' $b$ ' is the biomass in the non-AMF treatment.

Statistical analysis: SPSS program was used for all statistical analysis and the significance level was set at 0.05. Differences between AMF treatments were calculated for each plant species in monoculture and in competition separately, using a one-way analysis of variance (ANOVA). Differences between AMF treatments in RYT and aggressively index were also calculated with a oneway ANOVA.

\section{Results}

The total biomass of the plant was counted in all plants and the root nodules also counted for $T$. incarnatum. Biomass of T. incarnatum in monoculture was higher with AMF than without AMF (Figure 01). The number of root nodules of T. incarnatum in monoculture was also higher with AMF added compared to the when no AMF is added (Figure 02), While the biomass of A. odoratum in monoculture was lower with AMF than without (Figure 03).

But in mixture with T. incarnatum biomass of A. odoratum was hardly affected by AMF and the biomass T. incarnatum in mixture with T. incarnatum was higher in case of without AMF but with AMF the biomass of T. incarnatum was found low (Figure 04). However, the number of root nodules of T. incarnatum was much higher with AMF than without AMF (Figure 05). Competitive relationships were not influenced by AMF. The RYT was not significantly different between the treatments $(\mathrm{F}=0.06$, $\mathrm{P}=0.814$, one-way ANOVA; Figure 06) and the aggressively index was not significantly different in competition $(\mathrm{F}=2.623, \mathrm{P}=0.156$; one-way ANOVA; Figure 07) and was not significantly different from the without AMF treatment. 

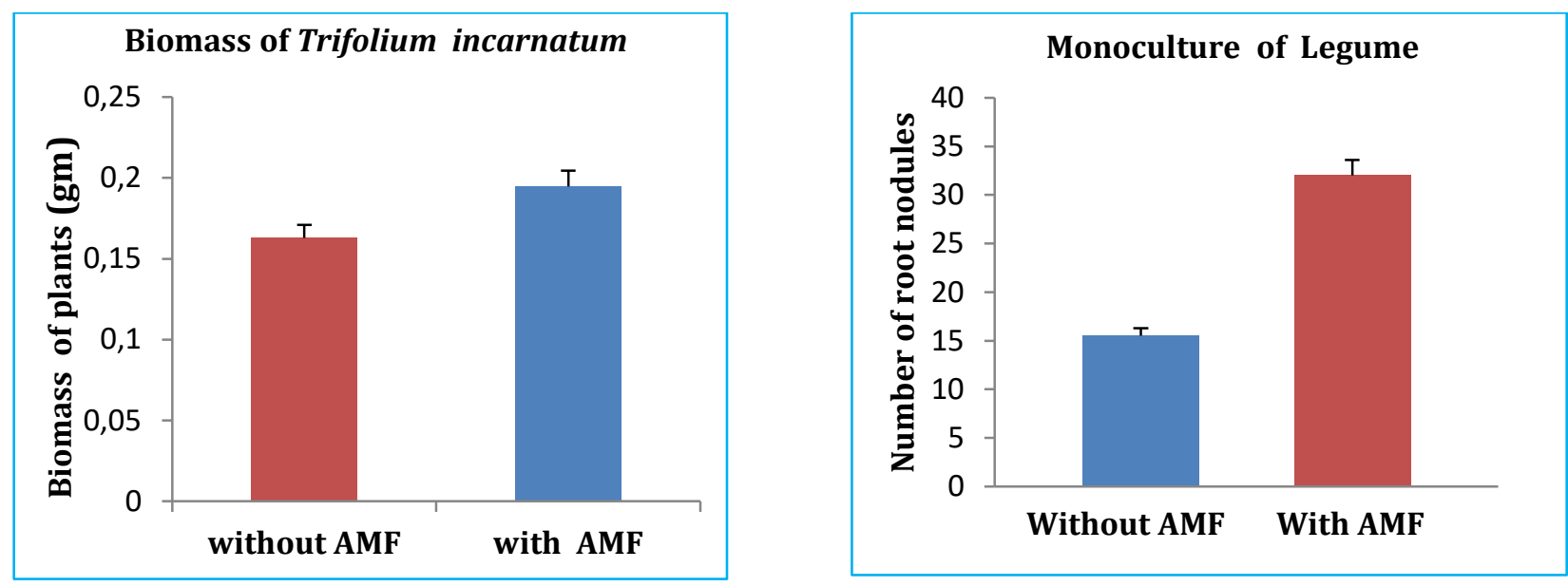

Figure 01. Biomass of T. incarnatum in monoculture. Figure 02. Root nodules of T. incarnatum in monoculture.
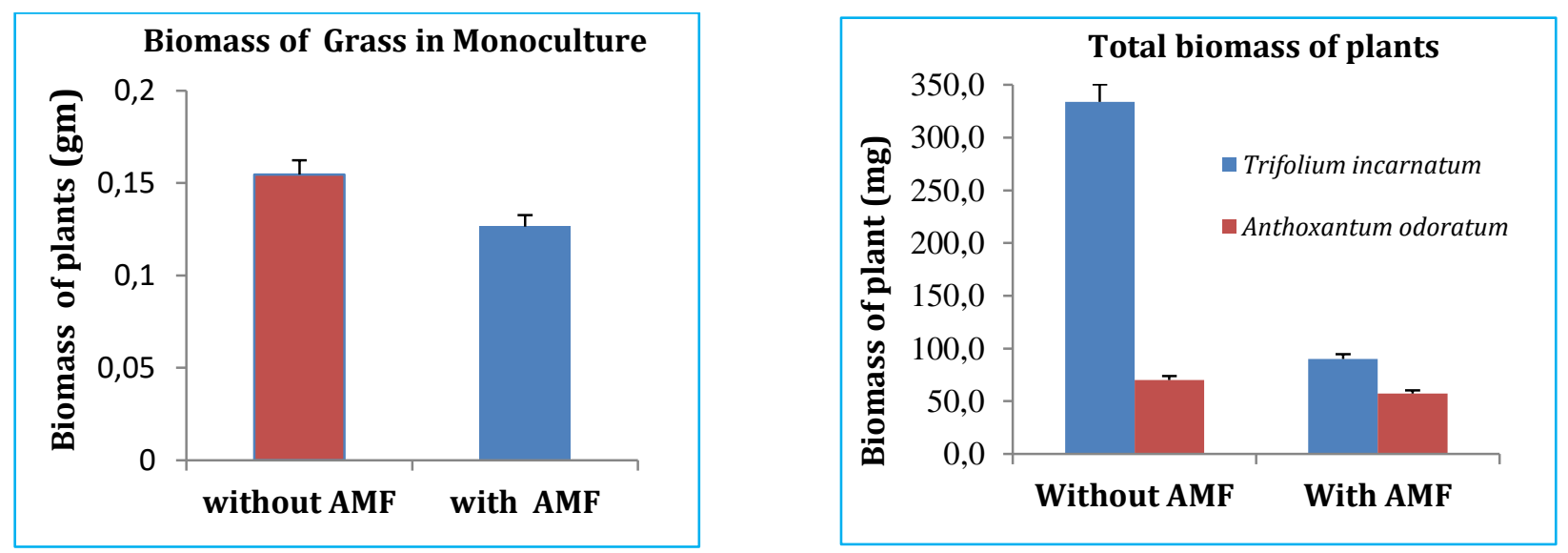

Figure 03. Biomass of A. odoratum in monoculture. Figure 04. Biomass of T. incarnatum \& A. odoratum in mixture.

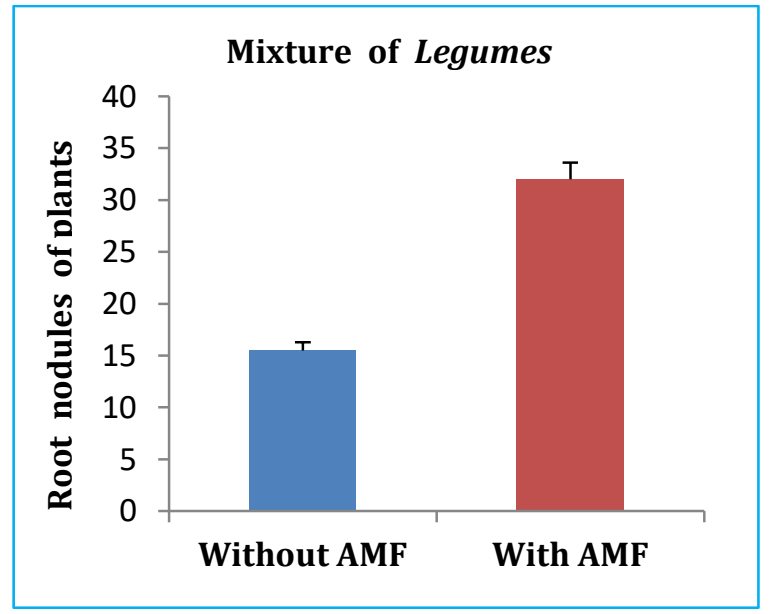

Figure 05 . Number of root nodules in mixture.

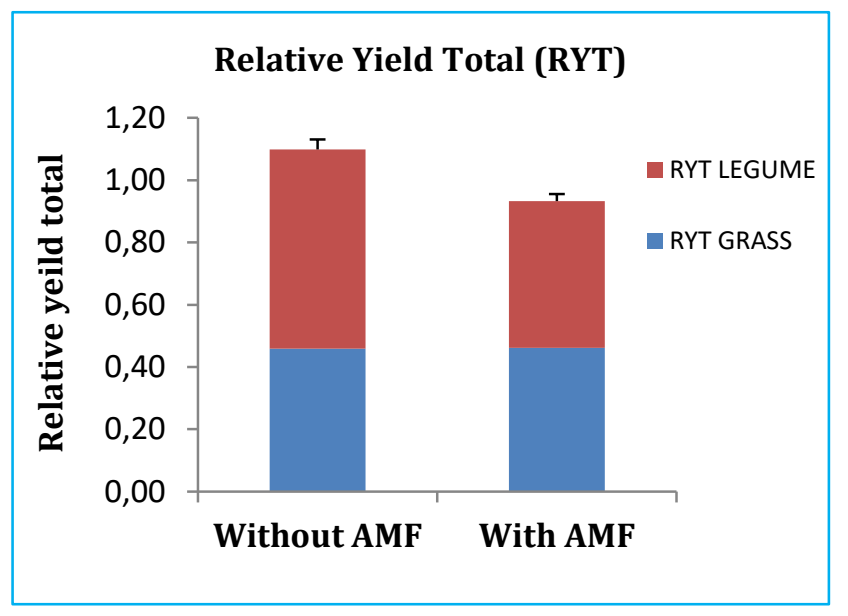

Figure 06. RYT in the competition between plants. 


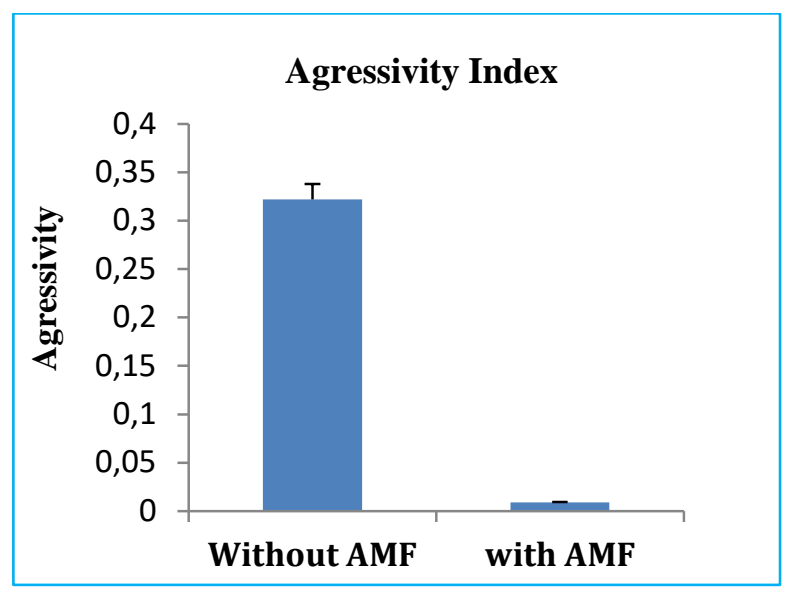

Figure 07. Aggressivity Index for the plants.

\section{Discussion}

The experiment revealed that AMF influence the plant growth, i.e., the biomass of T. incarnatum is favoured by the fungi .This is in accordance with first hypothesis that the biomass of legume plant increases with the presence of AMF and the number of root nodules of T. incarnatum is also positive to AMF compare to without AMF.

A. odoratum was negatively responsive to AMF in monoculture. This result is in agreement with other study studies that observed AMF have negative effect on some plants species (Verbruggen et al. 2011; Veiga et al. 2011). This is not unexpected as plants are often unresponsive or negatively responsive to AMF in pot experiments where root development is space limited (Graham and Abbott, 2000). Mycorrhizal growth depressions are attributed to AMF parasitism, where carbon (C) demand from the fungus exceeds the benefits of increased nutrient uptake (Veiga et al. 2011).

But grass plant remained unresponsive in competition with the presence of AMF. These results show that plant responses to AMF in monocultures cannot serve as a prediction for how AMF affect plants in competition with other species.

During competition, relative yield of legume plant increased yield in absence of AMF while the relative yield of the grass plant decreased or remain equal. From the figure of aggressivity index, it can be stated that competitive relationship changed in favour of legumes (aggressivity become lower) in presence of AMF. This is in accordance with our $4^{\text {th }}$ hypothesis that AMF had influence on the competitive relationship between $T$. incarnatum and $A$. odoratum. These results are in agreement with other studies. Several researchers observed AMF to alter competitive relationship between plants (Hamel et al. 1992; Hartnett et al. 1993; Hetrick et al.1994; West 1996; Tanja et al. 2007).

\section{Conclusion and recommendation}

This experiment revealed that AMF stimulates the plant growth of legume and negative effect on grass plant, and number of root nodules of legume plant has positive effect in monoculture and mixture. In case of competition betwwen plants, legume plant increased biomass in absence of AMF while the relative yield of the grass plant decreased or remain equal, and AMF affects the competitive relationship between legume and grass plant.

Further studies will be required to determine the effect of AMF on the biomass production of $T$. incarnatum and $A$. odoratum require further investigation in rather larger scale, while factors that affect the competitive relationship need to investigate more deliberately. 


\section{Acknowledgement}

This experiment was conducted for the partial fulfilment of Master of Organic Agriculture, Dept. of Organic Agriculture, Wageningen University, Wageningen, the Netherlands. The authors acknowledge the support of staff and laboratory facility for the course of Ecological Aspects of Bio-Interactions.

\section{References}

[1]. Aerts, R. (1999). Inter specific competition in natural plant communities: mechanisms, tradeoff and plant-soil feedbacks. Journal of Experimental Botany, 50, 29-37.

https://doi.org/10.1093/jxb/50.330.29

[2]. Allen, E. B., A. F. Allen, D. J. Helm, J. M. Trappe, R. Molina and E. Rincon. (1995). Patterns and regulation of mycorrhizal plant and fungal diversity. Plant and soil, 170, 47-62. https://doi.org/10.1007/BF02183054

[3]. Clay, K., Marks, S. and Cheplick, G. P. (1993). Effects of insect herbivory and fungal endophyte infection on competitive interactions among grasses. Ecology, 74,1767-1777. https://doi.org/10.2307/1939935

[4]. De Wilt, C. T. (1960). On competition.Verlagen Van Landbouwkundige Onderzoekingen, 66.

[5]. Fitter, A. H. (1997). Influence of mycorrhizal infection on competition of phosphorus and potassium by two grasses. New Phytologist, 79, 119-125. https://doi.org/10.1111/j.1469-8137.1977.tb02187.x

[6]. Graham J. H. and Abbott, L. K. (2000). Wheat responses to aggressive and nonaggressive arbuscular mycorrhizal fungi. Plant and Soil, 220, 207-218. https://doi.org/10.1023/A:1004709209009

[7]. Grime, J. P., Mackey, J. M. L., Hillier, S. H. and Read, D. J. (1987). Floristic diversity in a model system using experimental microcosms. Nature, 328, 420-422.

https://doi.org/10.1038/328420a0

[8]. Hamel, C., Furlan, V. and Smith, D. L. (1992). Mycorrhyzal effects on interspecific plants competition and nitrogen transfer in legume grass mixture. Crop Science, 32, 991-996. https://doi.org/10.2135/cropsci1992.0011183X003200040032x

[9]. Hart, M. M., Reader, R. J. and Klironmos, J. N. (2003). Plant co-existence mediated by arbuscular mycorrhizal fungi. Trends in Ecology and Evolution, 18, 418-423.

https://doi.org/10.1016/S0169-5347(03)00127-7

[10]. Hartnett, D. C., Hetrick, B. A. D., Wilson, G. W. T. and Gibson, D. J. (1993). Mycorrhizal influence on intra and inter-specific neighbour interactions among co-occurring prairie grasses. Journal of Ecology, 81, 787-795. https://doi.org/10.2307/2261676

[11]. Hetrick, B. A. D., Hartnett, D. C., Wilson, G. W. T. and Gibson, D. J. (1994). Effect of mycorrhizae, phosphorus availability, and plant-density on yield relationships among competinh tallgrass prairie grasses. Canadian Journal of Botany, 72, 168-176.

https://doi.org/10.1139/b94-023

[12]. Jakobsen, I., abbott, L. K. and Robson, A. D. (1992). External hyphae of vasicular-arbuscular mycorrhizal fungi associated with Trifolium subterraneum L. I. Spread of hyphae and phosphorus inflow into roots. New Phytologist, 120, 371-380.

https://doi.org/10.1111/j.1469-8137.1992.tb01077.x

[13]. Marler, M. J., Zabinski, C. A. and Callaway, R. M. (1999). Mycorrhizae indirectly enhance competitive effects of an invasive forb on a native bunchgrass. Ecology, 80, 1180-1186. https://doi.org/10.1890/0012-9658(1999)080[1180:MIECE0]2.0.CO;2

[14]. McGilchrist, C. A. and Trenbath, B. R. (1971). Revised analysis of plant competition experiments. Biometrics, 27, 659-671. https://doi.org/10.2307/2528603

[15]. Newman, E. I. (1988). Mycorrhizal links between plants: their functioning and ecological significance. Advances in Ecological Research, 18, 243-270.

https://doi.org/10.1016/S0065-2504(08)60182-8

[16]. Simard, S. W., Durall, D. M. and Jones, M. D. (2002). Carbon and nutrient fluxes within and between mycorrhizal plants. Mycorrhizal Ecology (eds. M. G. A. van der Heijden \& I. R. Sanders), Springer-Verlag, Berlin. pp. 33-74.

[17]. Smith, S. E. and Read, D. J. (1997). Mycorrhizal Symbiosis, 2nd edn. Academic press, London. 
[18]. Tanja r. Scheublin, Richard s. P. Van Logtestijn and Marcel g. A. Van der Heijden (2007). Presence and identity of arbuscular mycorrhizal fungi influence competitive interactions between plant species. Institute of Ecological Science, Vrije Universiteit, de Boelelaan 1085, 1081HV Amsterdam, the Netherlands. Journal of Ecology, 95, 631-638.

[19]. Van der Heijden, M. G. A. (2002). Arbuscular mycorrhizal fungi as a determinant of plant diversity: in search for underlying mechanisms and general principles. Mycorrhizal Ecology (eds M.G.A.van der heijden \& I.R.Sanders), Springer-Verlag, Berlin. pp. 243-265. https://doi.org/10.1007/978-3-540-38364-2_10

[20]. Van der Putten, W. H. and Peters, B. A. M. (1997). How soil-borne pathogens may effect plant competition. Ecology, 78, 1785-1795. https://doi.org/10.1890/0012-9658(1997)078[1785:HSBPMA]2.0.C0;2

[21]. Veiga, R. S., Jansa, J., Frossard, E. and van der Heijden, M. G. (2011). Can arbuscular mycorrhizal fungi reduce the growth of agricultural weeds. PLoS One, 6(12): e27825.

https://doi.org/10.1371/journal.pone.0027825

PMid:22164216 PMCid:PMC3229497

[22]. Verbruggen E, Kiers ET, Bakelaar PNC, Röling WFM, van der Heijden MGA. (2011). Provision of contrasting ecosystem services by soil communities from different agricultural fields. Plant and Soil, 1-82.

[23]. Werner, D. (1992). Symbiosis of Plants and Microbes. Chapman \& Hall, London.

[24]. West, H. M. (1996). Influence of arbuscular mycorrhizal infection on competition between Holcus lanatus and Dactylis glomerata. Journal of Ecology, 84, 429-438.

https://doi.org/10.2307/2261204 